CLINICAL STUDY

\title{
Impaired quality of life of patients with acromegaly: control of GH/IGF-I excess improves psychological subscale appearance
}

\author{
Maria P Matta, Elisabeth Couture, Laurent Cazals ${ }^{1}$, Delphine Vezzosi, Antoine Bennet and Philippe Caron \\ Department of Endocrinology and Metabolic Diseases, CHU Larrey, 31059 Toulouse, France and ${ }^{1}$ Department of Diabetes and Metabolism, CHU Rangueil, \\ 31059 Toulouse, France \\ (Correspondence should be addressed to P Caron who is now at Department of Endocrinology, CHU Larrey, 24 Chemin de Pourvouville, TSA 30030, \\ 31059 Toulouse Cedex 9, France; Email: caron.p@chu-toulouse.fr)
}

\begin{abstract}
Introduction: Acromegaly, a chronic disease caused by GH/IGF-I excess, has a major impact on quality of life (QoL).

Objective: To evaluate QoL of acromegalic patients in relation to control status of the disease.

Design and methods: Single center observational study including 93 patients with acromegaly recruited to complete QoL questionnaire (AcroQol). QoL was evaluated at least 3 months after surgery and/or medical treatment. Patients were divided into two groups: controlled (I) and uncontrolled (II) according to the latest consensus acromegaly 'control' criteria and further subdivided into four subgroups according to the previous pituitary adenoma surgery (Ib and IIb) or without surgery (Ia and IIa). Results: Mean GH $(0.81 \pm 0.47 \mathrm{ng} / \mathrm{ml})$ and IGF-I $(195 \pm 71 \mathrm{ng} / \mathrm{ml})$ values in group I were significantly lower than in group II (GH, $7.01 \pm 12.05 \mathrm{ng} / \mathrm{ml}$ and IGF-I, $513 \pm 316 \mathrm{ng} / \mathrm{ml} ; P<0.001)$. There was no difference in total AcroQol score, physical, or psychological scales between groups I and II. However, when adjusted to age and disease duration since diagnosis, patients of group I $(63 \pm 20 \%)$ showed an improved psychological subscale appearance than those of group II ( $58 \pm 17 \% ; P=0.035)$. In group II, IGF-I level was lower after surgery (IIa $=588 \pm 353$, IIb $=410 \pm 225 \mathrm{ng} / \mathrm{ml} ; P<0.038$ ), and psychological subscale appearance was significantly better in subgroup IIb $(64.9 \pm 18.1 \%)$ than in subgroup IIa who had medical treatment $(53.9 \pm 14.3 \% ; P=0.009)$.

Conclusion: QoL is severely impaired in acromegalic patients. Control of GH/IGF-I excess by surgery or medical treatment seems to have a positive impact on psychological subscale appearance.
\end{abstract}

European Journal of Endocrinology 158 305-310

\section{Introduction}

Acromegaly is an insidious chronic disease caused by hypersecretion of growth hormone (GH) and insulinlike growth factor-I (IGF-I), and is associated with an increased morbidity and mortality, mainly through cardiovascular, metabolic, and neoplastic complications. Increased life expectancy is directly related to the control of the disease. Current therapeutic armamentarium including transsphenoidal surgery, radiotherapy, and medical treatment with dopamine agonists, somatostatin analogs, and/or GH receptor antagonist drug (pegvisomant) induce biochemical cure in almost all patients with acromegaly $(1,2)$ according to consensus criteria (3). Previous reports demonstrated the efficiency of these treatments in reversing the mortality rate of patients to that of age-matched healthy subjects $(4,5)$. However, whether control of the disease improves quality of life $(\mathrm{QoL})$ gives rise to controversy (6).

The aim of the present clinical study was to assess QoL in relation to control status of the disease in a large cohort of treated acromegalic patients using the French validated version of the AcroQol questionnaire.

\section{Patients and methods}

Ninety-three acromegalic patients who attended our department between July 2004 and September 2006 were asked to complete the AcroQol French version questionnaire.

Patients were divided into two groups: controlled (I) and uncontrolled (II) groups according to remission criteria (nadir serum GH concentration after oral glucose tolerance test $(\mathrm{OGGT})<1 \mathrm{ng} / \mathrm{dl}$ or mean GH level $<2.5 \mathrm{ng} / \mathrm{ml}$ and age- and gender-specific IGF-I normal concentration).

Characteristics of patients, such as age, gender, duration of the disease since the diagnosis of acromegaly, previous and current treatment of acromegaly, and related co-morbidities were recorded by chart review. GH and IGF-I levels were measured at the time of completing the QoL questionnaire. 
GH assays were performed using a chemiluminescence technique (Nichols Institute diagnostics, San Clemente, CA, USA). The detection limit is $0.02 \mu \mathrm{g} / \mathrm{l}$ and the intraand inter-assay coefficient of variation (CV)s are 3.7 and $6.2 \%$ respectively. IGF-I assay was performed using a chemiluminescence technique (Nichols Institute Diagnostics). The detection limit is $6 \mu \mathrm{g} / \mathrm{l}$ and the intra- and inter-assay CVs are 5.2 and $5.7 \%$ respectively.

The study protocol was approved by the medical ethic committee and all subjects gave their written informed consent.

The acromegaly QoL questionnaire (AcroQol), originally developed in Spanish $(7,8)$ and was designed to assess QoL in patients with acromegaly. The questionnaire comprises 22 items covering physical and psychological aspects of acromegaly. The latter subdivided into 'appearance' and 'personal relation' subscales.

Each question has five possible answers scoring 1-5. Results are quoted as a percentage with a minimal score of $0 \%$ and a maximal score of $100 \%$ equating worse and best QoL respectively.

\section{Statistical analysis}

Stata statistical software (StataCorp., 4905, Lakeway Drive, College Station, TX 77845, USA) was used to perform data analysis. Data were expressed as mean \pm S.D. unless otherwise mentioned. Comparison between groups was done using uni- and multivariate regression analyses. $P \xi$ was calculated by multivariate regression analysis after adjustment for age and disease duration. In bivariate analysis, $\chi^{2}$ test or Fisher's exact test was used when appropriate to compare the distribution of qualitative variables between groups. Means of quantitative variables were compared using Student's $t$-test.
Spearman's rank-order correlation was used for nonparametric data. A $P$ value $<0.05$ was considered statistically significant.

\section{Results}

Ninety-three acromegalic patients ( 55 women/38 men; 26-85 years of age) with a mean time since acromegaly diagnosis of 9.5 years (0-38 years) completed the French version of QoL questionnaire (AcroQol). Two groups were identified: controlled (I, $n=36$ ) and uncontrolled (II, $n=57$ ) according to 'control' criteria. Only two patients were treated with pegvisomant, for those patients, control of the disease was defined by normal age- and sex-adjusted IGF-I level.

During treatment, 38 patients underwent pituitary surgery, 13 had radiotherapy, and 11 had both surgery and radiotherapy. Treatment with long-acting somatostatin analogs (slow-release lanreotide, somatuline autogel, sandostatin long-acting release (LAR)) were given to 71 patients and similar in 29 patients $(81 \%)$ in group I and 42 patients (74\%) in group II. Overall mean SMS analog treatment was 6.58 years (0-21.1 years). Six patients in the uncontrolled group did not receive any treatment for acromegaly as they were evaluated at the time of diagnosis, whereas two patients in the controlled group had only dopamine agonist treatment. Associated hypopituitarism was treated with hormonal replacement therapy in 19 patients (Table 1 ).

Mean GH $(0.81 \pm 0.47 \mathrm{ng} / \mathrm{ml})$ and IGF-I (195 \pm $71 \mathrm{ng} / \mathrm{ml}$ ) values in group I were significantly lower than in group II $(\mathrm{GH}, 7.01 \pm 12.05 \mathrm{ng} / \mathrm{ml}$ and IGF-I, $513 \pm 316 \mathrm{ng} / \mathrm{ml} ; \mathrm{P}<0.001)$. Obstructive sleep apnea syndrome was more frequent in group II (44\%) than in group I $(17 \% ; P<0.007)$. Joint-related complaints were found in $39 \%$ of patients in group I and $46 \%$ of

Table 1 Characteristics (age, gender, duration of the disease, modes of therapy, related co-morbidities, insulin-like growth factor-I, IGF-I and growth hormone, GH level) of controlled and uncontrolled patients with acromegaly.

\begin{tabular}{llll}
\hline Variable (group) & Controlled (I) & Uncontrolled (II) & P value \\
\hline$N$ & 36 & 57 & 0.0219 \\
Age (mean, years) & 58.4 & 52.0 & 0.001 \\
Male/female & 7 males/29 females (19.4\%) & 31 males/26 females $(54.3 \%)$ & 0.4133 \\
Years from diagnosis (mean) & 10.5 & 8.8 & 0.0032 \\
Mean GH (ng/ml) & $0.81 \pm 0.47$ & $7.01 \pm 12.05$ & 0.00001 \\
Mean IGF-I (ng/ml) & $196 \pm 71$ & $514 \pm 316$ & 0.900 \\
Treatment of acromegaly & 15 & 23 & 0.625 \\
Previous surgery & 5 & 6 & 0.851 \\
$\quad$ Surgery+radiotherapy & 10 & 16 & 0.287 \\
$\quad$ Surgery+SMS & 19 & 26 & 0.093 \\
SMS alone without surgery & 9 & 24 & 0.256 \\
Dopamine agonists & 0 & 2 & 0.416 \\
Pegvisomant & $15(41.6 \%)$ & $19(33.3 \%)$ & 0.076 \\
Associated complications & $4(11.1 \%)$ & $15(26.3 \%)$ & 0.007 \\
Hypertension & $6(16.6 \%)$ & $25(43.8 \%)$ & 0.523 \\
Diabetes & $14(38.8 \%)$ & $26(45.6 \%)$ & 0.851 \\
Sleep apnea syndrome & $7(19 \%)$ & $12(21 \%)$ & \\
Joint-related complaints & & & \\
Treated hypopituitarism & &
\end{tabular}


Table 2 Mean acromegaly quality of life (AcroQol) scores in controlled (I) and uncontrolled (II) groups of acromegalic patients. Comparison between groups using uni- and multivariate regression analyses.

\begin{tabular}{|c|c|c|c|c|}
\hline Group & I & II & $P$ value & $\boldsymbol{P} \xi$ \\
\hline$N$ & 36 & 57 & & \\
\hline Total AcroQol score & $59.8+17.9$ & $58.9+18.6$ & 0.816 & 0.386 \\
\hline Physical scale & $63.8 \pm 16.5$ & $65.0 \pm 18.3$ & 0.758 & 0.922 \\
\hline Psychological scale & $70.4 \pm 15.9$ & $68.8 \pm 15.7$ & 0.651 & 0.234 \\
\hline Psychological subscale 'appearance' & $63.1 \pm 20.0$ & $58.3 \pm 16.7$ & 0.215 & 0.035 \\
\hline Psychological subscale 'personal relationships' & $77.9 \pm 14.8$ & $77.9 \pm 17.0$ & 0.995 & 0.620 \\
\hline
\end{tabular}

$P \xi$ calculated by multivariate regression analysis after adjustment for age and disease duration.

those in group II $(P=0.523)$. Hypertension occurred in 15 patients in group I (36\%) and in 19 patients of group II $(57 \% ; P=0.416)$. Four patients $(36 \%)$ versus fifteen patients $(57 \%)$ had diabetes mellitus in groups I and II respectively $(P=0.076)$.

Except for age (group $\mathrm{I}=58$ years and group $\mathrm{II}=52$ years, $P=0.02)$ and gender $(19 \%$ male in group I and $54 \%$ male in group II, $P<0.001)$, disease duration, associated morbidities and treatment modalities were not significantly different between the two groups (Table 1).

In our cohort of 93 acromegalic patients, mean AcroQol score was 59.3 $18.3 \%$, and a weak and inverse correlation was observed between psychological subscale appearance score of AcroQol questionnaire and IGF-I value $(r=-0.22, P=0.039, n=89)$.

There was no significant difference in total AcroQol score, physical or psychological scales between groups I and II. However, when adjusted to age and disease duration, the patients of group I showed a significantly better psychological subscale appearance than those of group II ( $P=0.035$; Table 2$)$.

The patients were further divided into four subgroups according to previous pituitary adenoma surgery and control status of the disease. The clinical characteristics of the four subgroups are shown in Table 3.
In controlled group (group I) patients who have undergone pituitary surgery (group Ib) have a significantly longer disease duration $(16.7 \pm 10.3$ years) than those treated medically (group Ia; $6.1 \pm 6.5$ years, $P=0.006)$. In both groups, hypopituitarism was significantly associated with surgery: $40 \%$ in controlled group (group I; $P=0.013$ ) and $39.1 \%$ in uncontrolled group (group II; $P=0.009$ ).

Mean IGF-I was significantly lower in uncontrolled patients with previous surgery (group IIb) than in uncontrolled patients treated medically (group IIa; $P=0.0387)$.

There was no significant difference in age, sex ratio, associated morbidities, GH level, tumor volume (microversus macro-adenoma), and treatment with somatostatin analogs among the four groups (Table 3).

Neither total AcroQol score nor physical or psychological score differs among the four groups (Table 4). However, psychological subscale appearance was significantly better in group IIb than in group IIa $(P=0.009)$.

\section{Discussion}

In this cohort of treated patients with acromegaly, the total score of AcroQol questionnaire is $59 \pm 18 \%$

Table 3 Clinical characteristics of the four subgroups of acromegalic patients.

\begin{tabular}{|c|c|c|c|c|c|c|}
\hline \multirow[b]{2}{*}{ Variables } & \multicolumn{3}{|c|}{ Controlled (I) } & \multicolumn{3}{|c|}{ Uncontrolled (II) } \\
\hline & Surgery $(-)$ la & Surgery $(+) \mathrm{lb}$ & $P$ & Surgery $(-)$ Ila & Surgery $(+)$ llb & $P$ \\
\hline$N$ & 21 & 15 & & 34 & 23 & \\
\hline Age (years) & $56.6 \pm 14.4$ & $61.0 \pm 9.9$ & 0.310 & $53.61 \pm 13.9$ & $49.7 \pm 11.3$ & 0.274 \\
\hline Male (\%) & $3(14.2 \%)$ & $4(26.6 \%)$ & 0.418 & 18 (52.9\%) & 13 (56.5\%) & 0.790 \\
\hline Disease duration (years) & $6.1 \pm 6.5$ & $16.7 \pm 10.3$ & 0.0006 & $7.3 \pm 9.8$ & $11.1 \pm 8.4$ & 0.140 \\
\hline $\begin{array}{l}\text { Current treatment with SMS } \\
\text { analogs }\end{array}$ & $19 \overline{(90.4 \%)}$ & $10(66.6 \%)$ & 0.103 & $26(76.4 \%)$ & $16(69.5 \%)$ & 0.561 \\
\hline Radiotherapy & $0(0 \%)$ & $5(33.3 \%)$ & 0.008 & $2(5.8 \%)$ & $6(26.0 \%)$ & 0.051 \\
\hline $\begin{array}{l}\text { Hypopituitarism } \\
\text { Morbidities }\end{array}$ & $1(4.7 \%)$ & $6(40 \%)$ & 0.013 & $3(8.8 \%)$ & $9(39.1 \%)$ & 0.009 \\
\hline HTA & $11(52.3 \%)$ & $4(26.6 \%)$ & 0.176 & $12(35.2 \%)$ & $7(30.4 \%)$ & 0.703 \\
\hline SAS & $5(23.8 \%)$ & $1(6.67 \%)$ & 0.367 & $17(50 \%)$ & $8(34.7 \%)$ & 0.256 \\
\hline Diabetes & $2(9.5 \%)$ & $2(13.3 \%)$ & 1.000 & $12(35.2 \%)$ & $3(13 \%)$ & 0.074 \\
\hline Joint complaints & $10(47.6 \%)$ & $4(26.6 \%)$ & 0.302 & 19 (55.8\%) & 7 (30.4\%) & 0.058 \\
\hline Mean GH (ng/ml) & $0.8 \pm 0.5$ & $0.7 \pm 0.42$ & 0.3411 & $7.3 \pm 10.3$ & $6.5 \pm 14.5$ & 0.797 \\
\hline Mean IGF-I (ng/ml) & $214.3 \pm 74.6$ & $169.7 \pm 57.5$ & 0.0696 & $588.0 \pm 353$ & $410.2 \pm 225.5$ & 0.0387 \\
\hline
\end{tabular}


Table 4 Acromegaly quality of life (AcroQol) scores in four subgroups of acromegalic patients.

\begin{tabular}{|c|c|c|c|c|c|c|c|c|}
\hline \multirow[b]{2}{*}{ Variables } & \multicolumn{4}{|c|}{ Controlled (I) } & \multicolumn{4}{|c|}{ Uncontrolled (II) } \\
\hline & Surgery $(-)$ (la) & Surgery $(+)(\mathrm{lb})$ & $P$ & $P \xi$ & Surgery $(-)$ (Ila) & Surgery $(+)(\mathrm{Ilb})$ & $P$ & $P \xi$ \\
\hline$N$ & 19 & 15 & & & 26 & 23 & & \\
\hline Total score & $59.7 \pm 21.5$ & $60 \pm 12.1$ & 0.972 & 0.971 & $57.9 \pm 16.8$ & $60.4 \pm 21.5$ & 0.613 & 0.554 \\
\hline Scale 1 & $63.9 \pm 17.3$ & $63 . \overline{8} \pm 16.1$ & 0.992 & 0.609 & $65.1 \pm 17.9$ & $64.9 \pm 19.3$ & 0.957 & 0.906 \\
\hline Scale 2 & $70.5 \pm 18.7$ & $70.3 \pm 11.6$ & 0.961 & 0.751 & $67.5 \pm 13.9$ & $71 \pm \overline{18.3}$ & 0.406 & 0.332 \\
\hline Scale $2-1$ & $63.7 \pm 22$ & $62.4 \pm 15.6$ & 0.861 & 0.933 & $53.9 \pm 14.3$ & $64.9 \pm 18.1$ & 0.013 & 0.009 \\
\hline Scale 2-2 & $77.5 \pm 16.8$ & $78.7 \pm 12.3$ & 0.826 & 0.573 & $78.6 \pm 14.8$ & $77.0 \pm 20.3$ & 0.726 & 0.853 \\
\hline
\end{tabular}

Comparisons between groups using uni- and multivariate regression analyses. $P \xi: P$ values after adjustment to age and disease duration. Scale 1 , physical scale; scale 2, psychological scale; scale 2-1, psychological subscale 'appearance'; and scale 2-2, psychological subscale 'personal relationships'.

attesting that QoL is severely impaired in such acromegalic patients. Similar results were published previously in successfully treated patients (9) using a Finnish generic 15D instrument suggesting a degree of irreversibility related to a delay in diagnosis of acromegaly leading to irreparable damage. The most affected dimension is appearance, with a score of $60 \pm$ $18 \%$ and the least affected is personal relations, with a score of $78 \pm 16 \%(8,10)$. In a German population of acromegalic patients, the biochemically uncontrolled group showed significantly lower HR-QoL than the controlled group using the same criteria as the present study for defining remission status of the disease (11). Another study (12) demonstrated no correlation between biochemical control and any measure of QoL using AcroQol and several generic well-being tools such as psychological well-being schedule (PGWBS) and signs and symptoms score (SSS). In our cohort of treated acromegalic patients, we observed a weak and inverse correlation between psychological subscale appearance and IGF-I value. Recently, a negative correlation was also observed between changes in IGF-I levels and overall AcroQol score and its physical, psychological and appearance subdomains in treated acromegalic patients (13). Moreover, in a large European study including 817 patients with acromegaly treated with long-acting octreotide formulation (sandostatin LAR) for at least 3 months, an inverse correlation was observed between global AcroQol score, GH $(r=-0.076, P=0.03)$ and IGF-I $(r=-0.071$, $P=0.045)$ values (14), significant result due to the large number of patients included. Therefore, control of GH/IGF-I excess has an impact on QoL of acromegalic patients mainly through the most affected psychological subscale appearance.

In treated and well-controlled patients, persisting co-morbidities may have contributed to reduced QoL as previously reported (15). Hypertension occurred in $33-41 \%$ of our patients, diabetes mellitus was encountered in 11-26\%, whereas the most prevalent morbidity was joint-related complaints occurring in 39-45\%. The prevalence of these co-morbidities is comparable with epidemiological morbidity studies in active acromegaly $(15,16)$. Sleep apnea syndrome affects $60-70 \%$ of acromegalic patients (17). In our cohort,
$43.8 \%$ of the uncontrolled group suffered from sleep apnea syndrome versus $16.6 \%$ of the controlled group $(P<0.007)$. The lower prevalence of SAS in controlled group was expected as part of beneficial mediated effect of lower IGF-I on upper airway soft tissue $(18,19)$. In the present study, controlled group of acromegalic patients showed a significantly better subscale psychological appearance than those of uncontrolled group independent of age and disease duration. This finding might be related to lesser incidence of sleep apnea syndrome or 'snoring' representing one of the seven items of psychological subscale appearance.

Numerous studies have documented that controlling GH/IGF-I excess either by surgery or medical treatment ameliorates biochemical profile and reduces morbidity and mortality $(20,21)$. However, whether these improvements translate into positive impact on health-related QoL remains controversial. Conflicting data previously reported, showed that either a negative, neutral, or even positive influence on QoL of successfully treated acromegalic patients $(6,11,12)$. Furthermore, patients with uncontrolled disease who have undergone pituitary surgery showed better psychological subscale appearance than those treated medically. Despite the uncontrolled GH/IGF-I hypersecretion, patients who underwent surgery had significantly lower IGF-I level thus lower disease activity which could explain the positive impact on their psychological subscale appearance score. According to previous studies, reduction of tumor mass by surgery enhances the response to somatostatin analogs and increases the likelihood of achieving biochemical disease control $(22,23)$. Therefore, in such uncontrolled patients, surgical debulking may increase hormonal control, reduce morbidity, and ameliorate QoL. It is noteworthy that the positive impact of surgery in the uncontrolled group is higher than would have been expected given that patients who had undergone surgery presented a higher prevalence of hypopituitarism than patients treated with somatostatin analogs alone. It seems that the increased frequency of hypopituitarism after surgery in controlled and uncontrolled groups did not significantly affect the QoL of these patients. This might be explained by the fact that patients with hypopituitarism were on hormonal replacement therapy. Moreover, none had GH 
deficiency which is known to have the most negative impact on QoL in hypopituitarism and thirdly, AcroQol questionnaire does not cover areas of life affected by pituitary hormone deficiency and may not be a sensitive tool in the latter field $(24,25)$.

In the two groups (groups I and II), the majority of patients were treated with a somatostatin analog. Long-acting formulations of somatostatin analogs (octreotide LAR, slow-release lanreotide, somatuline autogel) are well tolerated and effective with regard to suppression of $\mathrm{GH}$ secretion and tumor shrinkage $(26,27)$. All acromegalic patients treated by long-acting forms of somatostatin analogs had monthly injections done by nurses of their neighborhood. Recently, a crosssectional study including 52 patients with treated acromegaly showed no difference in the AcroQol scores between controlled and uncontrolled groups (28). However, in the biochemically controlled group, patients treated with i.m. lanreotide injections had significantly worse QoL in comparison with those without lanreotide treatment. The negative impact of lanreotide treatment should be interpreted with caution. The major limitation of this study is the small sample size. Moreover, GH level was significantly higher in controlled patients who received lanreotide treatment than those with no medical treatment. This finding suggests that the lower the disease activity the better the QoL. Furthermore, i.m. injections of slow-release lanreotide administered every 2 weeks in a hospital setting might generate psychological distress and less of a sense of well-being in patients with controlled disease. However, it has recently been reported that training patients self- or partner administration of the new lanreotide autogel formulation may confer advantages in terms of clinic visits, independence and patient's wellbeing without compromising control of GH/IGF-I excess (29). Further investigations are mandatory to tailor the therapy based on a patient's individual requirements taking into consideration not only control of GH/IGF-I excess but also physical and psychological functions in patients with acromegaly.

\section{Acknowledgements}

The authors confirm that there is no source of funding relevant to the research reported in this manuscript and declare that there is no conflict of interest that would prejudice their impartiality.

\section{References}

1 Feenstra J, de Herder WW, ten Havea MTH, van den Beld AW, Feelders RA, Janssen JA \& van der Lely AJ. Combined therapy with somatostatin analogues and weekly pegvisomant in active acromegaly. Lancet 2005365 1644-1646.
2 Jorgensen JO, Feldt-Rasmussen U, Frystyk J, Chen JW, Kristensen LO, Hagen C \& Orskov H. Cotreatment of acromegaly with a somatostatin analog and a growth hormone receptor antagonist. Journal of Clinical Endocrinology and Metabolism 200590 5627-5631.

3 Giustina A, Barkan A, Casanueva FF, Cavagnini F, Frohman L, Ho K, Veldhuis J, Wass J, Von Werder K \& Melmed S. Criteria for cure of acromegaly: a consensus statement. Journal of Clinical Endocrinology and Metabolism 200085 526-529.

4 Beauregard C, Truong U, Hardy J \& Serri O. Long-term outcome and mortality after transsphenoidal adenomectomy for acromegaly. Clinical Endocrinology $20035 \mathbf{5 8 6}$ 861.

5 Swearingen B, Barker FG, II, Katznelson L, Biller BM, Grinspoon S, Klibanski A, Moayeri N, Black PM \& Zervas NT. Long-term mortality after transsphenoidal surgery and adjunctive therapy for acromegaly. Journal of Clinical Endocrinology and Metabolism 1998 83 3419-3426.

6 Woodhouse LJ, Mukherjee A, Shalet SM \& Ezzat S. The influence of growth hormone status on physical impairments, functional limitations, and health-related quality of life in adults. Endocrine Reviews 200627 287-317.

7 Badia X, Webb SM, Prieto L \& Lara N. Acromegaly quality of life questionnaire (AcroQoL). Health and Quality of Life Outcomes 2004213.

8 Webb SM. Quality of life in acromegaly. Neuroendocrinology 2006 $83224-229$.

9 Kauppinen-Makelin R, Sane T, Sintonen H, Markkanen H, Valimaki MJ, Loyttyniemi E, Niskanen L, Reunanen A \& Stenman UH. Quality of life in treated patients with acromegaly. Journal of Clinical Endocrinology and Metabolism 200691 3891-3896.

10 Webb SM, Badia X \& Surinach NL. Validity and clinical applicability of the acromegaly quality of life questionnaire, AcroQoL: a 6-month prospective study. European Journal of Endocrinology 2006155 269-277.

11 Trepp R, Everts R, Stettler C, Fischli S, Allemann S, Webb SM \& Christ ER. Assessment of quality of life in patients with uncontrolled vs. controlled acromegaly using the acromegaly quality of life questionnaire (AcroQoL). Clinical Endocrinology 200563 103-110.

12 Rowles SV, Prieto L, Badia X, Shalet SM, Webb SM \& Trainer PJ. Quality of life (QOL) in patients with acromegaly is severely impaired: use of a novel measure of QOL: acromegaly quality of life questionnaire. Journal of Clinical Endocrinology and Metabolism $2005903337-3341$.

13 Paisley AN, Rowles SV, Roberts ME, Webb SM, Badia X, Prieto L, Shalet SM \& Trainer PJ. Treatment of acromegaly improves quality of life, measured by AcroQol. Clinical Endocrinology 200767 358-362.

14 Webb SM, Colao A, Caron P, Corvalheiro M, Ertürk E, PokrajacSimeunovic A, Schopohl J, Tsagarakis S, Pearson IV, Badia X, Caglio S \& Vincenzi B. European prospective real-life observational study of quality of life in patients with acromegaly. Endocrine Abstracts 200611 OC20.

15 Biermasz NR, Pereira AM, Smit JW, Romijn JA \& Roelfsema F. Morbidity after long-term remission for acromegaly: persisting joint-related complaints cause reduced quality of life. Journal of Clinical Endocrinology and Metabolism 200590 2731-2739.

16 Podgorski M, Robinson B, Weissberger A, Stiel J, Wang S \& Brooks PM. Articular manifestations of acromegaly. Australian and New Zealand Journal of Medicine 198818 28-35.

17 Fatti LM, Scacchi M, Pincelli AI, Lavezzi E \& Cavagnini F. Prevalence and pathogenesis of sleep apnea and lung disease in acromegaly. Pituitary 20014 259-262.

18 Sze L, Schmid C, Bloch KE, Bernays R \& Brandle M. Effect of transsphenoidal surgery on sleep apnoea in acromegaly. European Journal of Endocrinology 2007156 321-329.

19 Buyse B, Michiels E, Bouillon R, Bobbaers H \& Demedts M. Relief of sleep apnoea after treatment of acromegaly: report of three cases and review of the literature. European Respiratory Journal 199710 1401-1404.

20 Kauppinen-Makelin R, Sane T, Reunanen A, Valimaki MJ, Niskanen L, Markkanen H, Loyttyniemi E, Ebeling T, Jaatinen P, 
Laine H, Nuutila P, Salmela P, Salmi J, Stenman UH, Viikari J \& Voutilainen E. A nationwide survey of mortality in acromegaly. Journal of Clinical Endocrinology and Metabolism 20059 4081-4086.

21 Biermasz NR, van Thiel SW, Pereira AM, Hoftijzer HC, van Hemert AM, Smit JW, Romijn JA \& Roelfsema F. Decreased quality of life in patients with acromegaly despite long-term cure of growth hormone excess. Journal of Clinical Endocrinology and Metabolism 200489 5369-5376.

22 Petrossians P, Borges-Martins L, Espinoza C, Daly A, Betea D, Valdes-Socin H, Stevenaert A, Chanson P \& Beckers A. Gross total resection or debulking of pituitary adenomas improves hormonal control of acromegaly by somatostatin analogs. European Journal of Endocrinology 2005152 61-66.

23 Colao A, Attanasio R, Pivonello R, Cappabianca P, Cavallo LM, Lasio G, Lodrini A, Lombardi G \& Cozzi R. Partial surgical removal of growth hormone-secreting pituitary tumors enhances the response to somatostatin analogs in acromegaly. Journal of Clinical Endocrinology and Metabolism 200691 85-92.

24 McMillan CV, Bradley C, Giannoulis M, Martin F \& Sonksen PH. Preliminary development of a new individualised questionnaire measuring quality of life in older men with age-related hormonal decline: the A-RHDQoL. Health and Quality of Life Outcomes 2003151.

25 Deijen JB, Arwert LI, Witlox J \& Drent ML. Differential effect sizes of growth hormone replacement on quality of life, well-being and health status in growth hormone deficient patients: a metaanalysis. Health and Quality of Life Outcomes 2005363.
26 Maiza JC, Vezzosi D, Matta M, Donadille F, Loubes-Lacroix F, Cournot M, Bennet A \& Caron P. Long-term (up to 18 years) effects on GH/IGF-1 hypersecretion and tumour size of primary somatostatin analogue (SSTa) therapy in patients with GHsecreting pituitary adenoma responsive to SSTa. Clinical Endocrinology 200767 282-289.

27 Cozzi R, Montini M, Attanasio R, Albizzi M, Lasio G, Lodrini S, Doneda P, Cortesi L \& Pagani G. Primary treatment of acromegaly with octreotide LAR: a long-term (up to nine years) prospective study of its efficacy in the control of disease activity and tumor shrinkage. Journal of Clinical Endocrinology and Metabolism 2006 91 1397-1403.

28 Hua SC, Yan YH \& Chang TC. Associations of remission status and lanreotide treatment with quality of life in patients with treated acromegaly. European Journal of Endocrinology 2006155 831-837.

29 Bevan JS, Newell-Price J, Wass JA, Atkin SL, Bouloux PM, Chapman J, Davis JR, Howlett TA, Randava HS, Stewart PM \& Viswanath A. Home administration of lanreotide Autogel ${ }^{\circledR}$ by patients with acromegaly, or their partners, is safe and effective. Clinical Endocrinology, 2007 (Epub ahead of print).

Received 8 December 2007

Accepted 14 December 2007 